\title{
Making Clinical Placements utilizing Mezirow's Transformative Theory of Adult Learning
}

\author{
Sheryl Cornelius EdD, MSN, RN, CNE
}

Coordinator of MSN Nurse Educator Track, Assistant Professor PSON and Blair College of Health, Queens University of Charlotte, 1900 Selwyn Ave., Charlotte, NC USA.

\section{Article Details \\ Article Type: Review Article \\ Received date: $13^{\text {rd }}$ October, 2019 \\ Accepted date: $04^{\text {th }}$ November, 2019 \\ Published date: $06^{\text {th }}$ November, 2019}

"Corresponding Author: Sheryl Cornelius, Coordinator of MSN Nurse Educator Track, Assistant Professor PSON and Blair College of Health, Queens University of Charlotte, 1900 Selwyn Ave, Charlotte, NC USA. E-mail: corneliuss@queens.edu Citation: Cornelius S (2019) Making Clinical Placements utilizing Mezirow's Transformative Theory of Adult Learning. J Comp Nurs Res Care 4: 150. doi: https://doi.org/10.33790/jcnrc1100150.

Copyright: $\left({ }_{0} 2019\right.$, This is an open-access article distributed under the terms of the Creative Commons Attribution License 4.0, which permits unrestricted use, distribution, and reproduction in any medium, provided the original author and source are credited.

\begin{abstract}
Adult learners in healthcare often go back to school while simultaneously working in a lower position so they may gain exposure to the area that they are seeking employment. For example, a nursing student may work part-time as a Certified Nurse Assistant (CNA) while they are in school to become a registered nurse (RN). This quality improvement (QI) project cataloged a problem identified in an undergraduate nursing program where students were being assigned a clinical rotation on the same unit that they worked as a CNA. Faculty noticed these students were not transitioning to the role of RN as quickly as their classmates that were on unfamiliar units for clinical rotation. By using Mezirow's Transformative Theory of Adult Learning and creating a disorienting dilemma for these students, a change in practice showed better outcomes for students in this transition. Students were able to achieve cognitive dissonance and change their worldview of the material by being placed on a unit for clinical in which they were unfamiliar.
\end{abstract}

Keywords: Transformative Theory of Adult Learning, Clinical Placement, Role Transition

"Routines may make you feel at ease and in control, but what a constant routine really does is dull your sensitivities... But when you go out of your way to experience new things, or when you let new things happen to you, your body creates brand new neural pathways that fuel your creative spark and enhance your memory" [1].

Literature reviews abundantly support experiential learning as an effective tool in higher education by citing Dewey, Freire, Kolb, and Mezirow and their theories in adult learning. Many students seeking healthcare degrees are also kinesthetic learners in which the hands on experience is beneficial to their long-term retention of material [2]. The most prevalent method utilized for undergraduate experiential learning in nursing is through clinical in a hospital facility or community-based clinic supervised by a clinical instructor. The most common in graduate nursing programs is a preceptorship in the field of their specialization [3].

Choosing a clinical site for this hands-on experience is difficult in any field. There are a number of barriers to overcome just to gain the privilege of utilizing that site. In healthcare in particular, those obstacles are many. There must be an affiliation agreement between the institution and the school. The student must be oriented to the facility's policy and procedures. There is often drug testing, criminal background checks, proof of immunizations, competency in basic life support, and waivers for confidentiality and privacy. There are often passwords and access codes created specifically for access to critical information needed to complete the experience. After all, the student is working with human subjects in healthcare and the public needs protection.

For this reason, many schools allow the student to complete their clinical experience in the same facility that they currently are employed, sometimes even in the same unit. In this case, the facility is familiar with the student and the student needs less orientation to policy and procedure. Some facilities even allow preferential treatment for their own employees because there is less security risk than choosing someone that is unknown. These are all good reasons for the facility to keep the employee in the same area they are as a student. What is best for the student?

\section{Theoretical Perspective}

According to Mezirow [4], all individuals have a particular view of the world based on their upbringing, culture, education, and life experience. If asked, many individuals will be able to verbalize their worldview and give rationale for their thinking. It is often well rehearsed and solidified in their mind based on causal assumptions they have collected over time. Mezirow contended that it takes a "powerful human catalyst, a forceful argument, or what he calls a disorienting dilemma" to change that point of view [5]. The educator must create this disorienting dilemma in many circumstances. Mezirow's Transformative Theory of Adult Learning emphasized that becoming critically reflective of one's worldview is the key to transforming one's frame of reference [6]. He also concluded that a "foreign learning environment" that allows one's preconceived ideas to be substantially tested would be a "profitable context for transformative learning" [7].

It is within this framework proposed by Mezirow [6] that the basis for this paper was conceived. Mezirow's transformational learning theory asserts that through reflection, active learning, and placing ourselves in uncomfortable situations we are allowing ourselves to develop an understanding of the world and how we see it [8]. The question to be investigated in this quality improvement project: Does the placement for clinical or practicum in the same area that they work 
impede the learning experience? Past course evaluations and conversations amongst faculty over the course of several semesters led to conclusions that essentially changed practice in clinical site placement in one Southeastern United States nursing program.

\section{Background}

Adult learners go back to school for many reasons but generally it is to change their vocation or to move up in the employment setting- they are not going to be doing the same thing after they finish their degree. For example, nursing students often seek employment as a nursing assistant (CNA) while they are in school to become a registered nurse (RN). They enjoy being involved in the care setting and often are exposed to more relatable situations than their classmates that have employment outside the healthcare setting. Unfortunately, their instructors may overlook many of these students thinking they are farther ahead of their classmates. There is an unspoken assumption that these students have less difficulty transitioning to the new role because they are familiar with healthcare [9]. Actually, research shows that nurses have a rockier transition because they must unlearn habits from one specialty area and relearn the new area [10].

"Learning may be defined as the process of making a new or revised interpretation of the meaning of an experience, which guides subsequent understanding, appreciation, and action" [6]. Everything we experience in life shapes our beliefs, our values, and how we will interpret future experiences. "What we perceive and what we fail to perceive and what we think and fail to think are powerfully influenced by habits of expectation that constitute our frame of reference" [4].

Critical reflection by the learner is the central component to the transformational theory. According to Mezirow learning as an adult is a process of development that "...is not a succession of agerelated steps and stages, but instead results from transformations of perspective in response to unexpected events or disorienting dilemmas" [6]. Choosing a new career path or degree process is definitely a "disorienting dilemma". Mezirow refers to this process as transformational learning. "A learner's values, beliefs, and assumptions compose the lens through which personal experience is mediated and from which one makes sense of the world. Mezirow calls this lens the meaning perspective. When this lens is found to be inadequate in accommodating some life experience, it can be replaced through transformational learning with a new perspective that is "more inclusive, discriminating, open, emotionally capable of change and reflective, ie, more developed" [8].

There will be numerous times in an adult's life when unexpected events cannot be understood and resolved using the individual's present way of thinking or perspective. The individual's perspective has come about through lived experiences, values, judgments, and beliefs that have come to be known as truths. When something comes along to challenge those beliefs and attitudes, a disorienting dilemma is created. This conflict that arises from simultaneously held beliefs and attitudes that are incongruent with the individual's known truths is referred to as cognitive dissonance. Such dissonance, Mezirow suggests, can be reduced through a critical reflection process. The job of faculty is to encourage this dissonance to influence the transformation. This can be done through activities in reflective practice and critical thinking.

\section{Case Scenario}

Let us look at a specific case to illustrate the problem at hand. Sandy, a 21 year old nursing student worked part-time on the weekends as a CNA on a medical surgical unit in a local hospital. She had worked on this same unit for two and a half years while she was in general education classes in preparation for her admission to the nursing program. She had performed this job enough that she knew how to start and end her day, what was in her scope of practice, and what should be reported to the RN in charge of the patients. Likewise, the staff of RN's and other disciplines on the unit also knew what Sandy could and could not do. They were comfortable knowing what she would handle when she was on the unit and what they could expect out of her for report. When Sandy started her first semester of nursing school that involved clinical rotations, shewas assigned to the unit that she currently worked for her rotation.

In order for Sandy to be successful in pursuit of a position as an RN her 'lens' of thinking needed to change to that of an RN. Since Sandy was placed on the same unit that she currently worked as a CNA this was difficult.Encouraging the dissonance needed to produce a transformation can be done by ensuring the student does not go to a facility for clinical where they are familiar with the work they performed as a CNA. It is also imperative that they begin to think like an $\mathrm{RN}$ and leave the CNA mindset behind.

Mezirow [4] states when an individual orients to an employment position,that individual's worldview constructs another layer. The routine developed to complete that job description becomes habit. All other staff recognize that individual in this role and do not recognize them in other ways.

Sandy was not immune to this recognition in her role as a CNA. When she arrived on the unit for clinical, several staff members smiled and good-naturedly said, "What are you doing here? It is not the weekend." Sandy explained each time that she was here as a nursing student and not as a CNA today. She wore her badge and uniform for the school and presented herself in her proper role. As the semester continued, she was asked on numerous occasions to perform duties of the CNA and to assist another CNA with their duties by staff on the unit. Sandy often just followed orders because the broader reason for being there was the care of the patient, in her mind. However, the act of doing these CNA duties took away from her time learning the role of the RN. The duties also stunted Sandy's ability to change her thinking from a CNA to an RN.

According to Mezirow's research, Sandy needed to be able to break out of the role of a CNA to be able to embrace the role of the RN. Even after continued reiterating of duties by the faculty member to Sandy and to the staff, she was unable to make the change on this unit. The lens with which Sandy viewed the world was that of a CNA and she was having trouble viewing the world of the RN in her clinical experience.

\section{Method}

Over the course of four semesters, 22 students fit the same circumstances as Sandy. These students were $64 \%$ Caucasian female, 14\% African American female, 9\% Asian American female, 9\% Caucasian male, and 5\% African American male. They were between the ages of 21 years old and 38 years old. Their clinical experience prior to entering the program ranged from 1- 8 years as a CNA. They were performing clinical in the same area that they worked in another role.

Institutional Review Board (IRB) approval was not deemed necessary by the institution for the QI project and the project gained approval from the Dean. Anecdotal conversations with each instructor gave like conclusions that the students on the same unit as they worked were having difficulty embracing the role of the RN because they could not take off the CNA hat that was expected of them in this scenario.The researcher approached each student informally to discuss their role as a student on the assigned unit. The informal interviews began with "How has your clinical assignment on the same unit in which you work impacted your learning in the nursing program?" The follow up was with open-ended questions to further illicit responses to the same topic.

\section{Results}

Many shared that it was difficult to rethink their duties for the day when they were in such familiar circumstance. Only one of the students in the 22 interviewed said they would not have preferred another unit for clinical. The responses all illustrated a theme signifying 
a difficulty in role transition and ability to be seen in the role they were currently playing. All interviews were documented and discussed with a second faculty member to norm the themes identified as prominent. A sample of students' comments were as follows:

- I consistently was overlooked for opportunities to practice my skills because it was assumed I already knew how to do things that I had seen performed on my unit.

- It was hard for me to get to do 'nursey' things when staff kept asking me to help with a bedpan or help them transfer a patient.

- I constantly had to remind myself, CNA was not what I was doing today.

- I wish they could have seen me as a student and not as an employee.

- I feel like everyone assumed I knew everything on this floor because I had worked here for so long. I did not know the RN stuff though.

- I wish I could have been somewhere that I was just a student instead of an employee playing the role of student today. It would have been easier.

It is imperative that each student have the best possible path for success in nursing school. Poor outcomes often lead to the student giving up on continuing their education, unneeded financial issues, and poor self-esteem in future endeavors. With the nursing shortage on the rise, making qualified nurses in a timely manner could be what saves the profession [11]. In an effort to retain students and set them up for success a change had to be made.

\section{The change in practice}

After sufficient anecdotal data proving students needed to be assigned to a unit that they were not currently familiar with, faculty began seeking information from the student prior to making clinical assignments. Students were asked at the beginning of each semester to create a notecard that answered the following questions:

1. Where do you currently work? (facility and unit)

2. In what capacity is your employment (CNA, ward secretary, tech).

3. Have you worked in healthcare prior to this semester? If so, where, in what capacity and for how long?

Once the students filled out their notecard, the faculty member created the clinical groups based on the findings in the cards taking care not to place a student on a unit that they were currently familiar. Extra time was given on the first day of the rotation for students to acclimate themselves to the new unit and to introduce themselves to the staff. Activities to ensure a quicker orientation were included such as a unit wide scavenger hunt and a "tip toe" through the electronic medical record. Both activities fostered engagement on the unit and encouraged familiarity with the new surroundings.

With this emphasis of the student being in a "Foreign learning environment" for their clinical experience, they were forced to become critically reflective of their own worldview [7]. As Mezirow [6] stated this is the key to transforming one's frame of reference. Over the next two semesters, faculty monitored students to identify if the changes made a difference in the student's ability to transition to the role of RN. They were looking to ensure the students were using critical reflection by being placed in the disorienting dilemma of an uncomfortable environment. While there was a longer introduction to the unit, faculty felt students' ability to transition to the role of RN was quicker than when on a unit in which they worked.

\section{Discussion}

This quality improvement project allowed faculty to utilize Mezirow's Transformational Learning theory to create the disorienting dilemma the student needed for their learning to take place. By creating an uncomfortable environment,where there were no habits that needed to be broken; they had a fresh slate to begin thinking like an RN. Some students were anxious at first going to a unit in which they were unfamiliar but expressed satisfaction in learning new things by the end of the semester. Clinical engagement was increased, faculty reported. Students were better prepared because they did not assume they already knew the unit.

\section{Limitations to the Study}

Although the study spanned four freshmen cohorts, the sample was small and was only based on one undergraduate program in the Southeastern United States. Future studies should include multiple courses to identify a wider range of data. A larger number over multiple colleges would identify significance across disciplines.

\section{Implications for the Program}

Utilizing this method appears to be creating a more successful transition to the role of $\mathrm{RN}$ for our nursing students coming in with prior experience in healthcare. Though the information gained was applicable to a successful change in practice, faculty felt the process should be more formalized next time and tied to a learning outcome in the course. Student satisfaction with the change was positive and faculty could see progress in the transition to the new role.

\section{Recommendations for future studies}

Based on this QI project faculty agreed that a qualitative study into the transition from CNA to RN may be beneficial as well as a comparison study of those that were not in healthcare to those that had been in another level of healthcare for long periods of time.

\section{References}

1. Patel, S (2016) Why feeling uncomfortable is the key to success. Forbes.

2. Li Y, Yu W, Liu C, Shieh S, Yang B (2014) An exploratory study of the relationship between learning styles and academic performance among students in different nursing programs. Contemporary Nurse: A J Aus Nurs Profession 48: 229-239.

3. Fritz E (2018) Transition from clinical to educator roles in nursing: An integrative review. J Nurs Professional Development 34: 67-77.

4. Mezirow J (1978) Perspective Transformation. Adult Educ Quarterly 28: 100-110.

5. Christie M, Carey M, Robertson A, Grainger P (2015) Putting Transformative Learning into Practice. Aus J Adult Learning 55: 10-30.

6. Mezirow J (1991) Transformative dimensions of adult learning. San Francisco, CA: Jossey-Bass.

7. Rennick J (2015) Learning that makes a difference: Pedagogy and practice for learning abroad. Teaching \& Learning Inquiry. 3: 71-88.

8. Strange H, Gibson H (2017) An investigation of experiential and transformative learning in study abroad programs. Frontiers: The Interdisciplinary J Study Abroad 29: 85-100.

9. Chicca, J, Benden S (2019) New-to-Setting Nurse Transitions. J Nurs Professional Development 35: 66-75.

10. Ashley C, Halcomb E, Brown A, Peters K (2018) Experiences of registered nurses transitioning from employment in acute care to primary health care- Quantitative findings from a mixed methods study. J Clini Nurs 271: 355-362.

11. Sylvestre J, Ulrich B, Johnson T, Spector N, Blegen M et al. (2017) A multistate study on new graduate transition to practice program: Return on investment. Nurs Economics 35. 